\title{
Hospitalidade na Dimensão Religiosa na Romaria Nossa Senhora de Caravaggio em Farroupilha, RS, Brasil
}

\author{
Rosalina Luiza Cassol Schvarstzhaupt ${ }^{\mathrm{a}}$ \\ Vania Beatriz Merlotti Herédiab
}

\section{Resumo}

Este artigo tem como objetivo descrever algumas ações que ocorrem na romaria ao Santuário Nossa Senhora de Caravaggio no município de Farroupilha, RS, à luz da hospitalidade religiosa oferecida pelos membros da Igreja aos peregrinos. 0 estudo valese de aparato conceitual acerca da hospitalidade e religiosidade no turismo religioso e tem como referência básica os estudos de Boff, Baptista, Lashley, Grassi, Correia e de documentos da Igreja Católica. A pesquisa é de natureza qualitativa e suas entrevistas foram realizadas com representantes da Igreja que atuam ou atuaram no santuário no período da romaria. Os questionamentos buscam apurar a percepção do conceito de hospitalidade da Igreja. Os resultados apontam para um empenho da Igreja em atender a demanda de serviços essenciais e promover e ampliar a dinâmica da hospitalidade. A romaria é um fenômeno relevante que desloca milhares de peregrinos que retornam ao local anualmente e fortalecem a devoção em relação à Santa, estimulando o turismo religioso.

Palavras-chave: Hospitalidade; Religiosidade popular; Santuário Nossa Senhora de Caravaggio; Igreja Católica; Turismo religioso.

\section{Abstract \\ Hospitality in the religious dimension in the pilgrimage to Our Lady of Caravaggio/Farroupilha/RS/Brazil}

This proposal is intended to describe some actions that take place during the Pilgrimage to the Shrine of Our Lady of Caravaggio, in the town of Farroupilha, RS, in the light of the religious hospitality that is offered to pilgrims by sectors of the Church. The study uses the conceptual apparatus of hospitality and religiosity in religious tourism, whose basic reference sources are the studies of Boff, Baptista, Lashley, Grassi, Correia and documents of the Catholic Church. The research is qualitative and the interviews have been conducted with representatives of the Church, who work or used to work in the Shrine during the pilgrimage. The questions seek to determine what the perception of the concept Church hospitality is. The results indicate that the Church is committed to meeting the demands for essential services, in addition to promoting and expanding the dynamics of hospitality. The pilgrimage is a relevant phenomenon that draws thousands of pilgrims who return to the site every year, thus strengthening the devotion to the Saint and stimulating religious tourism.

Keywords: Hospitality; Popular Religiosity; Shrine of Our Lady of Caravaggio/ Farroupilha/RS; The Catholic Church; Religious Tourism.

a. Doutoranda em Turismo e Hospitalidade pela Universidade de Caxias do Sul (UCS), Caxias do Sul, RS, Brasil. E-mail: rlcassol@gmail.com

b. Possui pós-doutorado em História Econômica pela Università degli Studi di Padova, Padova, VN, Itália. Professora de pós-graduação em Turismo e Hospitaliade na UCS. E-mail: vbmhered@gmail.com 


\section{Resumen}

\section{Hospitalidad en la dimensión religiosa en la romería Nuestra Señora de Caravaggio, Farroupilha/RS, Brasil}

La presente propuesta tiene como objetivo describir algunas acciones que ocurren en la Romería al Santuario Nuestra Señora de Caravaggio en el municipio de Farroupilha/RS, a la luz de la hospitalidad religiosa ofrecida por los sectores de la Iglesia a los peregrinos. El estudio se vale de aparato conceptual acerca de la hospitalidad y religiosidad en el turismo religioso y tiene como referencia básica estudios de Boff, Baptista, Lashley, Grassi, Correia y de documentos de la Iglesia Católica. La investigación es de naturaleza cualitativa y las entrevistas se realizaron con representantes de la Iglesia que actúan o actuaron en el Santuario en el período de la romería. Los cuestionamientos buscan apurar la percepción del concepto de hospitalidad de la Iglesia. Los resultados apuntan a un empeño de la Iglesia en atender la demanda de servicios esenciales y promover y ampliar la dinámica de la hospitalidad. La romería es un fenómeno relevante que desplaza a miles de peregrinos que regresan al lugar anualmente y fortalecen la devoción hacia la Santa, estimulando el turismo religioso.

Palabras clave: Hospitalidad; Religiosidad Popular; Santuario Nuestra Señora de Caravaggio/Farroupilha/RS; Iglesia Católica; Turismo Religioso.

\section{INTRODUÇÃo}

0 tema da hospitalidade tem atraído interesse no meio acadêmico neste tempo marcado por grande mobilidade humana, decorrente de fatores econômicos, político-sociais e culturais em diversos espaços geográficos. Na dimensão religiosa, as peregrinações têm apresentado crescente fluxo em direção aos lugares sagrados em todo o mundo, fomentando o turismo religioso, com reflexos na economia, na cultura e na sociedade.

Diante desse contexto, este estudo tem como objetivo analisar a hospitalidade oferecida pela Igreja Católica aos peregrinos que participam da romaria ao Santuário de Nossa Senhora de Caravaggio, em Farroupilha, a qual acontece anualmente em torno do dia 26 de maio. 0 município de Farroupilha está localizado no nordeste do estado do Rio Grande do Sul, distante 111 quilômetros da capital, Porto Alegre.

É importante especificar que o Santuário de Nossa Senhora de Caravaggio, em Farroupilha, é o maior santuário religioso do sul do Brasil pelo fluxo de peregrinos. Localizado a seis quilômetros do centro da cidade, anualmente, recebe milhares de fiéis provindos de diversos estados brasileiros e de inúmeros países. 0 local atrai anualmente mais de 1,5 milhões de peregrinos. Nos dias da romaria, esse número gira em torno de 300 mil peregrinos.

Nossa Senhora de Caravaggio é padroeira do município e da região colonial italiana e o dia em que é celebrada sua aparição é feriado municipal. Nos dias da romaria, ocorre um grande fluxo de peregrinos de localidades vizinhas que se dirigem ao santuário, principalmente a pé, pois a grande maioria procede de Caxias do Sul, distante 18 quilômetros do local. Em 2016, a romaria de Caravaggio foi declarada bem cultural de natureza imaterial de Caxias do Sul. 0 santuário está situado num local elevado em relação a seu entorno, proporcionando uma bela vista paisagística com vales, vegetação e ar próprio de montanha. 
A história escrita e relatos atuais sugerem que o espírito de acolhimento faz parte da identidade da comunidade local assimilada pela tradição. Essa circunstância é percebida no empenho de aproximadamente mil pessoas entre residentes e as que se deslocam para o local a fim de prestar colaboração através de serviço voluntário nos dias da romaria.

A devoção à Nossa Senhora de Caravaggio foi trazida ao local pelos primeiros imigrantes italianos que aí se estabeleceram em 1876, vindos da região norte da Itália. Conforme a história narrada por Bertuol (1950), a aparição ocorreu em época de disputas de território entre Milão e Veneza e conflitos na Igreja. Era 26 de maio de 1432 quando Maria, mãe de Jesus Cristo, aparece e se identifica a uma simples camponesa, chamada Joaneta, a quem diz que vem anunciar a paz (Bertuol, 1950; Zorzi, 1986). Maria confia-lhe a missão de levar a mensagem aos governantes e ao povo, e pede que voltem às práticas cristãs católicas, como penitência, jejum às sextas-feiras e ir à igreja rezar nos sábados de tarde em agradecimento pelos castigos afastados. Além disso, Maria pede que no local de sua aparição seja construída uma capela (Bertuol, 1950).

A primeira capela, a qual deu origem ao atual santuário, em Farroupilha, foi construída pela iniciativa das 22 famílias que para aí migraram. Com espaço para mais de 100 pessoas, sua inauguração deu-se em 1879, ano considerado da fundação do Santuário de Caravaggio. Em 1885, o quadrinho com a estampa da aparição, objeto da devoção e que atualmente está exposto no mobiliário que sustenta o conjunto estatuário dentro do santuário, foi substituído pelas imagens esculpidas por Pietro Stangherlini, escultor da época que residia em Caxias do Sul/RS. O santuário atual foi construído em estilo romano no período de 1945 a 1963 e dispõe de capacidade para 2 mil pessoas. Além do santuário antigo, o espaço conta com uma rádio, capela dos ex-votos, sala de confissões, espaços de eventos, restaurantes, local de venda de artigos religiosos e demais estruturas de apoio.

\section{METODOLOGIA}

O estudo classifica-se como exploratório e de natureza qualitativa. 0 método utilizado foi a análise textual discursiva que, por meio da criação de categorias analíticas, permite examinar as narrativas dos entrevistados. 0 suporte metodológico baseou-se na abordagem teórico-metodológica de Moraes e Galiazzi (2007), que consideram a análise textual discursiva como uma opção de análise para pesquisas de natureza qualitativa e de caráter hermenêutico.

A coleta de dados foi realizada através de uma pesquisa de campo, por meio de entrevistas individuais guiadas e gravadas, com sujeitos que tiveram envolvimento com a romaria de Nossa Senhora de Caravaggio, em Farroupilha, com experiências vivenciadas no período entre 1940 a 2018. De acordo com os critérios estabelecidos para a pesquisa, foram realizadas 24 entrevistas entre os dias 23 de dezembro de 2016 e 19 de abril de 2018, as quais constituíram o corpus da pesquisa. A amostra foi constituída por sacerdotes, religiosas, agentes de pastoral e moradores do local. 


\section{APROXIMAÇÕES AO CONCEITO DE HOSPITALIDADE}

A hospitalidade vem ocupando um lugar de evidência no campo da discussão filosófica e científica, originado pelas adversidades decorrentes da globalização, que provoca migrações humanas, violência de tribos e vizinhos mais fortes diante do caos econômico e a miséria nos países mais fragilizados economicamente. 0 entendimento a respeito do significado do termo "hospitalidade" tem se manifestado amplo e complexo.

Um ponto de aproximação que parece prevalecer nas abordagens dos teóricos é de que a hospitalidade reporta ao tratamento de acolhida para com o "outro". Esse tratamento remete a gestos que envolvem amabilidade, afabilidade, gentileza, atenção, cordialidade, delicadeza, polidez, fineza, doçura e meiguice, e que se expressam na atitude de abertura ao outro que surge na perspectiva de ser solicitado ou convidado a compartilhar um espaço de reciprocidade, mediante regras, ritos e leis não escritas.

A hospitalidade caracteriza uma virtude, uma qualidade daquele que se conforma com o considerado correto e desejável do ponto de vista da moral, da religião e do comportamento social, mas também significa a assimilação da tensão entre seus contrários. A hospitalidade também pode ser interpretada pelas suas ambiguidades quando não é vista pela sua totalidade e apresenta uma série de restrições que podem nascer da própria compreensão do conceito de hospitalidade e hostilidade.

No âmbito religioso, a hospitalidade traz o traço da transcendência, característica que perpassa as diversas religiões. No Cristianismo, a hospitalidade passa a se expressar mais efetivamente através da criação das primeiras instituições de caridade e hospitalidade a partir do ano 321, quando o imperador romano Constantino reconhece o direito de a Igreja Católica receber doações (Godi, 2011). 0 espírito de acolher aos mais necessitados e não atendidos pelas estruturas da sociedade deram origem ao que hoje conhecemos como as Santas Casas, hospitais criados pela Igreja Católica, e que tem grande expressão também na contemporaneidade, juntamente com outras instituições de beneficência e assistência social ${ }^{1}$.

A atitude de acolher, na Igreja Católica, traz a memória do cuidado, da atenção e da disposição de receber bem aquele que chega. Essa ideia está impregnada no imaginário coletivo, e aquele que se dirige à comunidade religiosa tem a expectativa do acolhimento às suas necessidades. As influências da sociedade de consumo na contemporaneidade têm fortes consequências e implicações no comportamento individual e coletivo, atingindo toda a sociedade e provocando desafios maiores aos que se identificam com a causa cristã.

Grassi (2011) observa que o convite, a acolhida, a caridade e a solidariedade parecem ser formas vizinhas e derivadas de uma forma inicial de hospitalidade. Num gesto de compensação, a hospitalidade implica a introdução em um espaço e a instalação de um ritual de acolhida. 0 espaço a ser penetrado pode ser um espaço geográfico, que envolve os componentes urbano e doméstico; ou um espaço psíquico, o qual implica a penetração num território, o território do outro.

1. Os institutos de beneficência administrados pela Igreja Católica no mundo incluem: 5.158 hospitais, 16.523 postos de saúde, 612 leprosários, 15.679 casas para idosos, doentes crônicos e pessoas com deficiência e 78.088 instituições de outros tipos ("Vaticano", 2016). 
Grassi (2011) ainda considera a questão do "tempo" implicada na hospitalidade, isto é, há um tempo para a hospitalidade. A autora observa que a condição do hóspede compreende o não permanecer, uma vez que, se assim o fizer, este se torna membro e se instala no espaço. Portanto, "ao hóspede só se pode atribuir um direito de residência temporária, pois assimilar-se a uma comunidade é perder o status de hóspede" (Grassi, 2011, p. 46). Dessa forma, a hospitalidade é uma etapa que não pode traduzir uma disposição constante dos seres, mas que se dirige sempre a novos parceiros temporários. Assim sendo, a hospitalidade se caracteriza por um rito de passagem ou de iniciação dos vínculos sociais, uma dádiva temporária de um espaço.

Correia (2014) compreende que a hospitalidade revela-se como um dos caminhos para a construção da identidade cristã na comunidade de fé, argumentando que seu exercício, além de ser testemunho eloquente para os de fora, cria um ambiente caloroso para os de dentro. Correia considera que, em todas as civilizações, a história da relação das pessoas, grupos e povos registra muitos momentos de hospitalidade e de hostilidade, bem como manifesta a importância e o valor que cada sociedade deu e dá à pessoa humana. Para o autor, não há civilização que se construa à margem da sociedade. Considera que a própria Sagrada Escritura acentua, na sua globalidade, a necessidade e a importância da hospitalidade, pois em seus textos sempre promove e aconselha, mesmo se, por vezes, também aconselha prudência em seu exercício, como indicado no livro da Sabedoria ("Bíblia", 1983, p. 21-34).

Godi (2011) refere que a Igreja, como símbolo de casa da misericórdia, é um lugar que reúne condições específicas fundadas no princípio do amor ao próximo e de acolhida fraterna do outro, que a vinculam desde o seu surgimento à prática da hospitalidade. A Igreja constitui um lugar destinado a acolher a comunidade dos fiéis na intenção de aproximá-la de Deus, lugar da hospitalidade espiritual, onde aquele que crê é acolhido na morada sagrada e, por consequência, convidado a viver a experiência com o transcendente.

0 marco doutrinal da Igreja Católica é essencialmente de caráter humano e tem como centralidade Jesus Cristo, que é o ícone referencial da história humana ao anunciar um projeto de vida integral aos que aderem a sua proposta (Conferência Nacional dos Bispos do Brasil [CNBB], 1993). Embora o cristão católico tenha o conhecimento do caminho a percorrer na vida de fé, sua prática é exigente e demanda empenho, dedicação, escuta e afeto, que se expressam no apelo à abertura incondicional ao outro, que surge como suplicante ou convidado, para compartilhar um espaço na reciprocidade. Essas atitudes, com grande frequência, desafiam valores que prevalecem na sociedade.

\section{A HOSPITALIDADE COMO VIRTUdE E ÉTICA}

A hospitalidade, no âmbito religioso, traz em si o traço da transcendência que perpassa as religiões. Boff (2012) assinala que a hospitalidade é por excelência a virtude dos nômades, migrantes e peregrinos. 0 autor considera que de certa maneira todos somos peregrinos e de alguma forma merecedores de hospitalidade pois, sem as pessoas, comunidades e povos não alimentam a reciprocidade entre si nem reforçam os laços de paz e de amizade. 
Boff (2005) compreende a hospitalidade como uma das quatro virtudes centrais para um convívio verdadeiramente humano, juntamente com a convivência, a tolerância e a comensalidade. A vivência destas virtudes pode contribuir para um resgate da ética e da espiritualidade para a construção de um futuro de sustentabilidade para a humanidade. As virtudes constituem o mundo das excelências e dos valores com um apelo utópico de potencialidade para transportar a pessoa humana a horizontes mais abertos. A hospitalidade de uns para com os outros é a base, nos dizeres das escrituras judaico-cristãs, com o fundamento de que "todos somos hóspedes nesta terra e não temos aqui morada permanente" (Boff, 2005, p. 13).

Na dinamicidade da sociedade, Boff (2005) alude a Thomas Kuhn e Fritjof Capra, que introduzem no debate contemporâneo a questão da mudança de paradigmas e que reconhecem estar emergindo um outro tipo de percepção da realidade. Ao paradigma do inimigo e do confronto, é necessário contrapor o paradigma do aliado, do hóspede e do comensal. Boff (2005, p. 30) sustenta que "do confronto devemos passar à conciliação e da conciliação chegar à convivência $\mathrm{e}$ da convivência à comunhão e da comunhão à comensalidade". A prática dessas virtudes fornece a base para um futuro de esperança com novos valores, sonhos, forma de organizar arquitetonicamente os conhecimentos, tipo de relação social e forma de dialogar com a natureza.

Boff observa que as tradições religiosas são importantes para a busca de um consenso ético mínimo entre os humanos, pois guardam virtualidades insuspeitas. Pela religião, os povos concretamente encontraram um meio para fazer valer e garantir o caráter universal e incondicional de um consenso mínimo. Para o autor, "a religião funda a incondicionalidade e a obrigatoriedade das normas éticas muito melhor do que a razão abstrata ou discurso racional parcamente convincentes e só acessíveis por alguns setores da sociedade" (Boff, 2009, p. 80).

A atitude de acolher traz a memória do cuidado, da atenção e da disposição de receber bem aquele que chega. Essa ideia está impregnada no imaginário coletivo e aquele que se dirige à comunidade religiosa tem essa expectativa do acolhimento. Entretanto, no momento histórico atual, num contexto marcado pelos traços do secularismo, as influências incutidas e assimiladas na sociedade de consumo trazem fortes implicações no modo de comportamento individual e coletivo em relação ao acolhimento. A acolhida traz à luz a estrutura básica do ser humano e a compreensão de que nossa existência acontece porque de uma forma ou de outra fomos acolhidos. Boff (2005) sustenta que o sentir-se rejeitado e excluído é o pior sentimento que envolve o ser humano.

Outra visão de hospitalidade é a de Baptista (2002, p. 157), que trata a hospitalidade como "um modo privilegiado de encontro interpessoal marcado pela atitude de acolhimento em relação ao outro" e que vê na relação de proximidade uma possível forma de abraçar verdadeiramente a aventura da descoberta, de realização e de superação de nós mesmos. Dessa forma, a hospitalidade apresenta-se como experiência fundamental construtiva da própria subjetividade e por meio da qual deve ser potenciada em todas as suas modalidades e contextos da vida.

Baptista discorre sobre a dimensão ética da hospitalidade e evidencia a necessidade de criar e alimentar lugares de hospitalidade, nos quais possam surgir a consciência de um destino comum e o sentido de responsabilidade capazes de motivar a ação solidária. Salienta que, sem a capacidade de sermos tocados, 
física e espiritualmente, pelos acontecimentos que expõem a vulnerabilidade do outro, qualquer esforço racional será inútil. A autora lembra os infortúnios humanos que continuam a marcar o nosso tempo e argumenta que a experiência de contato e a relação de hospitalidade permitem que a sensibilidade humana se torne possível. A hospitalidade permite romper com o ciclo egoísta a partir do momento em que outrem faz sua entrada em nosso meio. Dessa forma, o egoísmo só é possível como consciência e escolha deliberadas, e não mais como egoísmo inocente (Baptista, 2002).

Baptista (2008, p. 8) reitera que "a identidade pessoal alimenta-se dos laços de enraizamento temporal e estes carecem da vinculação a um ambiente natural, cultural e relacional, e portanto a um território de referência". A autora considera que as formas de organização territorial influenciam os estilos de pertença comunitária com a força de condicionar decisivamente as trajetórias de vida e interação social. Nesse sentido, a interpelação da alteridade contribui para animar a capacidade ou dom da bondade. Nesse sutil excesso de hospitalidade, emergem os atos que exprimem a sociabilidade humana, pois a bondade reside no fato de nos darmos a nós mesmos para que um sopro de bem faça transbordar a devoção familiar, a amizade, a obrigação profissional e a responsabilidade cívica.

Outro autor que colabora para a compreensão da hospitalidade no sentido de explicá-la como um comportamento social que expressa a vida coletiva é Lashley (2004, p. 14), que aborda a hospitalidade no domínio privado e que considera que "a família nuclear introduz os indivíduos em regras, rituais, normas e costumes que modelam as atividades de hospitalidade no cenário social". 0 cenário doméstico contribui para a oferta da hospitalidade e proporciona a oportunidade de situar o indivíduo e a família no contexto da civilidade. Os motivos da atividade doméstica que envolvem os aspectos nutricionais e altruísticos contribuem para criar um ambiente seguro e para moldar as expectativas da oferta não doméstica da hospitalidade. Por outro lado, os hóspedes prestam sua contribuição como agentes na avaliação da interação social dos indivíduos e das famílias.

Desta forma, Lashley compreende a hospitalidade como um conjunto de comportamentos originários da própria base da sociedade. A partilha e a troca dos frutos do trabalho, junto com a mutualidade e a reciprocidade, são a essência da organização coletiva e do senso de comunidade. 0 autor afirma que os atos de contribuir com o abastecimento do alimento coletivo e de partilhá-lo são a base de obrigações e direitos que sustentam a hospitalidade. Assim, as atividades relacionadas à hospitalidade proporcionam condições de avaliação social dos indivíduos e ajudam no desenvolvimento de laços sociais.

\section{OS SANTUÁRIOS RELIGIOSOS E A FÉ POPULAR}

Os santuários no mundo acolhem milhões de peregrinos anualmente, com um público cada vez mais heterogêneo e complexo. Para a Igreja Católica "pelo nome de santuário entende-se a igreja ou outro lugar sagrado, aonde os fiéis, por motivo de piedade, em grande número acorrem em peregrinações, com aprovação do Ordinário do lugar" (Conferência Episcopal Portuguesa, 1983, p. 212).

Grande parte dos santuários cristãos estão relacionados à Maria, mãe de Jesus Cristo, e a situações que envolvem sua "aparição" em tempos, lugares e culturas 
diversas. Ao que comumente chamamos de "aparições e revelações particulares" a Igreja Católica define como "experiências de ordem psíquica. . . fenômenos extraordinários que não se podem pressupor, mas dos quais temos inúmeros relatos de experiências" (CNBB, 2009, p. 15).

o Código de Direito Canônico estabelece que nos santuários sejam colocados à disposição dos fiéis meios de salvação mais abundantes, com o anúncio cuidadoso da palavra de Deus e o fomento da vida litúrgica, principalmente por meio da celebração da Eucaristia, da penitência e ainda do cultivo de formas aprovadas de piedade popular (“Bíblia”, 1983).

As peregrinações estão relacionadas à religiosidade popular e vinculadas aos santuários e à experiência religiosa. A religiosidade popular compreende gestos rituais, atos de culto, relatos e celebrações, e caracteriza-se por ser "uma religiosidade típica atribuída ao ser humano médio, desprovido de formação teológica especial" (Mattai, 1993, p. 1001).

Por religiosidade popular, Foralosso (2003) entende a efetividade da fé e da religião nos comportamentos humanos. Trata-se de uma experiência universal em que cada povo exprime de forma diversa sua visão de transcendência, natureza, sociedade e história através das mediações culturais. Religiosidade popular, portanto, não se relaciona necessariamente à revelação cristã. 0 termo "popular" se refere explicitamente aos sujeitos da experiência religiosa.

No documento do Vaticano Evangelii Nuntiandi (evangelização no mundo moderno), o Papa Paulo VI (1975) chamou a atenção para a riqueza da piedade popular, recordando que ela manifesta uma sede de Deus que somente os simples e os pobres podem conhecer e que os torna capazes de atos de generosidade e de sacrifícios até o heroísmo, quando se trata de manifestar a fé. Essa piedade comporta um sentido agudo dos atributos de Deus: paternidade, providência e presença amorosa constante, e gera atitude interior raramente observada no passado com a mesma intensidade: paciência, sentido da cruz na vida cotidiana, desprendimento, abertura aos outros e devoção (Paulo VI, 1975).

0 mesmo documento adverte as limitações dessa manifestação religiosa, pois acha-se frequentemente aberta à penetração de muitas deformações da religião, como, por exemplo, as superstições. Outro aspecto a considerar é que a religiosidade popular permanece com frequência apenas no nível das manifestações cultuais, sem expressar ou determinar uma verdadeira adesão de fé e pode, ainda, levar à formação de seitas, pondo em perigo a verdadeira comunidade eclesial. Se essa religiosidade, porém, for bem-orientada, sobretudo mediante uma pedagogia da evangelização, ela é algo que contém riqueza de valores. Portanto, ao considerar os aspectos positivos, o documento prefere chamá-lo de "piedade popular", no sentido de "religião do povo", em vez de religiosidade.

\section{RESULTADOS E DISCUSSÃo}

Com vistas a responder às questões norteadoras da pesquisa acerca da hospitalidade oferecida pela Igreja na romaria ao Santuário de Nossa Senhora de Caravaggio, foram feitas entrevistas individuais e guiadas. E, da análise dessas entrevistas, nasceram duas categorias analíticas: o sentido da hospitalidade da Igreja e o sentido da peregrinação. Por meio dessas categorias, é possível 
entender o sentido que a Igreja atribui à hospitalidade e como vê o caminho da peregrinação.

\section{O sentido da hospitalidade da Igreja}

Os sujeitos da pesquisa indicaram que o entendimento acerca do sentido da hospitalidade da Igreja aproxima o significado de "hospitalidade" ao de "acolhimento", entretanto, este último é considerado como o mais apropriado para o tratamento da questão no âmbito religioso.

As narrativas revelam que as ações que representam a hospitalidade da Igreja e, portanto, o acolhimento envolvem principalmente as atitudes de relação com a pessoa que chega ao espaço religioso e dizem respeito a dar atenção, receber bem, escutar, cuidar, ajudar a rezar, respeitar, conduzir, integrar, compreender, dar uma resposta de esperança e acolher em diversas condições, como nas angústias, no desespero, no choro, no sorriso, mas sobretudo na angústia e no desespero.

$\mathrm{O}$ acolhimento como fenômeno humano e relacional foi abordado por Santos, Perazzolo e Pereira (2014) como aquilo que se instala no espaço constituído entre dois sujeitos que desejam acolher e ser acolhidos, e que se revela no empenho da comunidade local que se dedica genuinamente para receber os peregrinos, oferecendo-lhes o possível para atendê-los integralmente.

Nos relatos, a hospitalidade é vista como um meio de acolhimento espiritual:

É proporcionar que a pessoa possa dizer o que ela sente, o que ela espera, o que ela sofre, o que ela espera da Igreja, o que a Igreja tem para dizer a ela naquele momento. (E8) ${ }^{2}$

Encontrei acolhimento porque o padre me escutou, sentiu o que eu estava vivendo.... o acolhimento não foi um julgamento que o padre fez de minha pessoa, foi o que eu pude expor, ou seja, no Santuário de Caravaggio eu encontrei, da parte do padre, o acolhimento. $O$ acolhimento que não é julgamento, é escutar. (E8)

Conforme Grassi (2011), a acolhida, a caridade e a solidariedade se assemelham porque constituem uma forma inicial de hospitalidade. Num gesto de hospitalidade e de acolhimento, o peregrino é introduzido em um espaço geográfico e, ao mesmo tempo, psíquico. 0 espaço geográfico corresponde ao trajeto que culmina no santuário e o espaço psíquico proporciona um território de transcendência no âmbito da fé. 0 acolher na romaria implica colocar-se à disposição das pessoas e dos peregrinos, sintonizando a necessidade de contato do ser humano.

Nos relatos dos entrevistados o acolher é "compreender o coração humano, além das palavras, aquilo que de fato se passa no âmago das pessoas" (E5). A hospitalidade da Igreja é acolhimento, compreensão, entendimento, cuidado, palavra de esperança. $\mathrm{O}$ ser humano constitui um ser em movimento. E como tal, a prática religiosa tende a proporcionar-lhe recursos para que exerça sua autonomia no caminho existencial.

Nesse sentido, revelam-se também relatos de outros entrevistados ao expressarem que "acolher é ouvir, entender e dar uma resposta de fé, amor e esperança para que a pessoa possa continuar a caminhada da vida" (E21).

2. Letra "E": forma abreviada para representar "Entrevistado". 
O santuário é este lugar de referência de muitas pessoas, mas que depois do retorno dos peregrinos é sempre um retorno diferente, renovado, em que muitos dizem "Olha, eu de vez em quando preciso vir aqui para renovar a minha vida, para encontrar paz, para encontrar uma palavra de consolo, para encontrar um conselho, para encontrar os sacramentos". (E5)

O cuidado na Igreja se expressa no interesse que temos na vida das pessoas que vêm ao templo, que está como que abraçando cada uma das pessoas. (E7)

A hospitalidade da Igreja é "a acolhida da pessoa não apenas do corpo, mas é muito mais, é a acolhida das angústias, a acolhida de um choro se precisar, de um sorriso, a acolhida da pessoa integral; é acolher sobretudo no seu desespero, na sua angústia" (E23).

Grassi (2001) fala de um tempo para a hospitalidade, isto é, um espaço de tempo que não se estenda indefinidamente, pois a permanência implica assimilar-se à comunidade e tornar-se membro, com o que cessaria o status de visitante ou hóspede. Desta forma, a hospitalidade oferecida ao peregrino na romaria é uma dádiva temporária de um espaço onde ele é acolhido e onde lhe são proporcionados os recursos disponíveis: a escuta, espiritualidade, espaços de conforto físico e psíquico, e palavras de esperança para seguir a vida de forma renovada.

\section{O sentido da peregrinação}

Quanto à pergunta acerca "do sentido de as pessoas fazerem a peregrinação ao santuário", as narrativas dos entrevistados apresentam uma diversidade de motivações, em que se destacam a gratidão por graças alcançadas, a busca de uma experiência de Deus, a busca de fortalecimento da fé e o sentido de "ser um caminho". Os documentos oficiais da Igreja abordam a vocação humana de estar a caminho nesta terra para uma existência que vai além dela. 0 caminhar é uma constante na vida humana na busca de algo sempre mais elevado. A experiência humana de um sacerdote, revelada em sua fala, mostra que " $O$ sentido do caminhar é sempre mostrar para nós que nós somos seres que não estamos concluídos, somos seres em projeto" (E7).

A gente vê hoje que esse simbolismo fala muito, de caminhada, de convidar, de fazer uma peregrinação. Não deixa de ser também uma atitude um pouco de sacrifício, de ir até lá, de visitar. Então o povo expressa nessas atitudes a sua religiosidade, ele quer fazer algo que acha que vai lhe fazer bem e com isso possa agradar e encontrar Deus. (E9)

Grande parte dos peregrinos que se deslocam de Caxias do Sul para o santuário nos dias da romaria realizam o trajeto de aproximadamente 18 quilômetros a pé. $\mathrm{O}$ fortalecimento da fé pode ser visto na fala de um morador local, agente de pastoral, que também se fez peregrino e viveu a experiência de colocar-se a caminho e vivenciar o que o momento oferece.

A pessoa que vem de Caxias ela carrega Caxias nas costas, porque ela carrega a casa, ela carrega a fábrica, carrega a escola, carrega o hospital... Ela carrega aquela esperança, carrega conseguir aquela graça... O peregrino é uma pessoa com estatura 
igual, é uma pessoa frágil igual, mas ele se sente um gigante, ou nos sentimos gigantes quando estamos em romaria. (E14)

Alguns sacerdotes manifestaram relatos de peregrinos acerca de suas buscas e necessidade de preencher a vida com a fé e expressar sua gratidão a Deus, através da romaria. "Eles estão vindo para buscar fé, agradecer a vida, e ser bem recebido para poder sentar e rezar" (E3). "Não há chuva, não há tempo ruim que afaste o desejo dela [pessoa] de ir rezar, de participar dos sacramentos, de agradecer" (E9).

"Mas padre, eu vim aqui porque eu necessito dentro de mim dar o passo da fé. Eu necessito crer em Deus". Reconhecendo tudo isso lhe faltava algo mais. "Preciso dar o passo da fé, porque isso tudo não me basta. Isso tudo me é pouco. Eu preciso dar o passo da fé". Buscam um momento de oração, um momento de confissão, um momento de espiritualidade. Vêm para encontrar a acolhida humana das pessoas. (E5)

Algumas falas dos entrevistados mostram como os peregrinos expressam sua fé e expectativa ao estarem no espaço do santuário.

Ir na frente da imagem de Nossa Senhora rezar e tocar na imagem e, se conseguir, encontrar com um sacerdote. (E9)

Muitos vão lá desabafar a tristeza, a angústia que eles têm, ou em si ou na família, ou na sociedade, um contratempo que existe na vida deles. (E10)

Esse experimento de recorrer a alguém que realmente te escuta. Porque quem faz uma caminhada, que vem aqui... Tem testemunhos que a gente escuta, são testemunhos muito reais, muito fortes da parte de quem os conta que fica muito difícil questionar. Esta experiência forte de pedir e ser atendido, de algo concreto que me acompanha, isso faz as pessoas virem aqui. (E13)

Na crise humana, de hoje, de ontem e de sempre, ela gira em torno disso, "ninguém escuta ninguém", só por necessidade, só por obrigação. (E17)

O fato é que esta obra é uma obra de Deus e que foge do nosso controle. Nos foge! Por mais que a gente tente preparar os ambientes e tudo o mais, mas é uma história da mão de Deus que vai conduzindo, e, que ali Nossa Senhora decidiu sentar para nos acolher. (E5)

As narrativas nas entrevistas evidenciaram o espírito de solidariedade impregnado nos sujeitos envolvidos nos trabalhos que dão suporte às romarias por meio do serviço de voluntariado. As informações fornecidas dão conta de que todas as famílias, com pessoas em diversas idades, colaboram voluntariamente nos serviços relacionados à romaria em todas as estruturas funcionais que são oferecidas. Baptista (2008) vê na relação de partilha um espaço para que as coisas do mundo transformem-se em conteúdos de interação e adquiram valor e sentido, numa relação em que "dando, trocando e retribuindo" coisas, as pessoas alimentam uma cadeia relacional que transcende a simples circulação e permuta de bens, conforme observado por Mauss (2003). A narrativa de um morador 
local visivelmente dedicado a contribuir para a romaria explicita o amor ao serviço comunitário e o papel da vocação do voluntário.

Quem descobre essa vocação do voluntariado e participa é uma pessoa que dentro de si carrega um tesouro muito grande. . é a pessoa que trabalha mais em casa, ou na fábrica, ou num outro ambiente de trabalho dele. Segundo, é a pessoa que nunca diz não, sempre está disposta. Terceiro, é a pessoa que mais sobra tempo. E o quarto, quando a pessoa está na rua, se a pessoa se detém a olhar essa pessoa aí é a pessoa que mesmo sofrendo, mesmo carregando [problemas], o voluntário é aquela pessoa que se dispõe a servir, não é um blindado, é uma pessoa que sofre como qualquer um, tem doenças, tem os problemas de família, mas é a pessoa que mais tem sorriso....E a pessoa que não consegue descobrir essa vocação aí, também tem as dificuldades, só que aí ela carrega só uma situação: carrega só o sofrimento. Por isso fica uma pessoa fechada, fria, parece um ferro. (E14)

Como aborda Lashley (2004), a hospitalidade revela-se num conjunto de comportamentos originários da base da sociedade. Os gestos de partilha e troca dos frutos do trabalho, junto com a mutualidade e a reciprocidade, constituem a essência da organização coletiva e do senso de comunidade. Estes traços podem ser notados na fala de um sacerdote envolvido na organização da romaria ao descrever a ação dos envolvidos nos serviços do evento religioso.

Eram em torno de mil pessoas trabalhando, quase que 100\% tudo gratuitamente, para atender bem os romeiros.... A dedicação gratuita é também um dos fatores que marca muito quem colabora com o santuário. (E17)

\section{CONSIDERAÇÕES FINAIS}

A hospitalidade parece requerer um adjetivo para ser explicitada quando se refere ao âmbito religioso. A hospitalidade da Igreja tem a ver com "acolhimento" uma vez que a expectativa de quem a ela chega, ou recorre a seus recursos, busca suprir principalmente necessidades relacionadas à dimensão espiritual, enquanto a hospitalidade em si, na percepção dos sujeitos da pesquisa, representantes da Igreja, está associada à ideia de serviço que envolve o aspecto material.

A gratuidade, o escutar, cuidar, compreender e compadecer-se com o sofrimento do outro são expressões que remetem à interioridade da pessoa, à sua condição espiritual e que envolvem também a perspectiva da transcendência.

O santuário é visto como um lugar de acolhimento que oferece aos peregrinos uma resposta aos seus anseios. Atender aos peregrinos torna-se quase uma missão no sentido de promover o atendimento espiritual, estar disponível para a escuta, olhar para o outro e oferecer consolo.

A riqueza das entrevistas possibilita entender como aqueles que atuam nas peregrinações utilizam a hospitalidade como uma ferramenta de acolhimento que promove o retorno desse peregrino e de sua família por diversas décadas, caracterizando-o como um peregrino de retorno.

Outro resultado que a pesquisa evidencia é o preparo dos membros da Igreja no acolhimento. As ações de hospitalidade aos peregrinos por parte dos sacerdotes 
e da própria comunidade revelam o envolvimento que têm com a romaria e como atuam frente às demandas que nascem dessas peregrinações. A resposta que o peregrino tem por parte da Igreja faz com que haja um fortalecimento das práticas devocionais que alimentam a busca religiosa.

\section{REFERÊNCIAS}

Baptista, I. (2002). Lugares de hospitalidade. In C. M. de Moraes (Org.), Hospitalidade: reflexões e perspectivas (pp. 157-164). Barueri, SP: Manole.

Baptista, I. (2008). Hospitalidade e eleição intersubjetiva: sobre o espírito que guarda os lugares. Revista Hospitalidade, 5(2), 5-14.

Bertuol, O. (1950). Milagrosa rainha de Caravaggio. Caxias do Sul, RS: Mitra Diocesana de Caxias do Sul.

Bíblia: mensagem de Deus. (1983). São Paulo, SP: Loyola.

Boff, L. (2005). Virtudes para um outro mundo possível. Hospitalidade: direito e dever de todos (vol. 1). Petrópolis, RJ: Vozes.

Boff, L. (2009). Ethos mundial: um consenso mínimo entre os humanos. Rio de Janeiro, RJ: Record.

Boff, L. (2012). Saber cuidar. Petrópolis, RJ: Vozes.

Conferência Episcopal Portuguesa. (1983). Código de Direito Canônico (4⿳a ed.). Braga, BR: Editorial Apostolado da Oração. Recuperado de http://bit.ly/2srKvZT

Conferência Nacional dos Bispos do Brasil. (1993). Catecismo da Igreja Católica. Petrópolis, RJ: Vozes.

Conferência Nacional dos Bispos do Brasil. (2009). Aparições e revelações particulares. Brasília, DF: Edições CNBB.

Correia, J. A. S. (2014). A hospitalidade na construção da identidade cristã. Braga, BR: Universidade Católica Editora.

Foralosso, M. (2003). Religiosidade popular. In L. Borrielo, E. Caruana, M. R. Del Genio, \& N. Suffi (Orgs.), Dicionário de mística (pp. 915-917). São Paulo, SP: Paulus.

Godi, P. (2011). Igreja: a Casa da Misericórdia. In A. Montandon (Org.), O livro da hospitalidade: a acolhida do estrangeiro na história e nas culturas (pp. 605-617). São Paulo, SP: Senac.

Grassi, M. C. (2011). Transpor a soleira. In A. Montandon (Org.), O livro da hospitalidade: a acolhida do estrangeiro na história e nas culturas (pp. 45-53). São Paulo, SP: Senac.

Lashley, C. (2004). Para um entendimento ético. In C. Lashley, \& A. Morrison (Orgs.), Em busca da hospitalidade: perspectivas de um mundo globalizado (pp. 2-24). Barueri, SP: Manole.

Mattai, G. (1993). Religiosidade popular. In S. Fiores, \& T. Goffi (Orgs.), Dicionário de espiritualidade (2ª ed., pp. 1000-1010). São Paulo, SP: Paulus.

Mauss, M. (2003). Sociologia e antropologia (P. Neves, trad.). São Paulo, SP: Cosac Naify.

Moraes, R., \& Galiazzi, M. C. (2007). Análise textual discursiva. Ijuí, RS: Unijuí.

Paulo VI. (1975). Evangelii Nuntiandi. Libreria Editrice Vaticana. Recuperado de http://bit.ly/ $2 \mathrm{Sw} \log \mathrm{U}$

Santos, M. C. dos, Perazzolo, O. A., \& Pereira, S. (2014). A hospitalidade numa perspectiva coletiva: o corpo coletivo acolhedor. In M. C. dos Santos, \& I. Baptista (Orgs.), Laços sociais: por uma epistemologia da hospitalidade (pp. 49-63). Caxias do Sul, RS: Educs. 
Vaticano: Estatísticas da Igreja Católica 2016.(2016).Agência Fides. Recuperado dehttp://bit.ly/ 2MuXpNC

Zorzi, B. (1986). Nossa Senhora de Caravaggio no Brasil. Farroupilha, RS: Mitra Diocesana de Caxias do Sul.

Recebido em: 08/08/2018

Aprovado em: 19/04/2019

\section{CONTRIBUIÇÕES}

Rosalina Luiza Cassol Schvarstzhaupt: Definição do problema de pesquisa e objetivos; desenvolvimento da proposição teórica; realização da revisão bibliográfica e fundamentação teórica; escolha dos procedimentos metodológicos; coleta de dados; análise de dados; elaboração de tabelas, gráficos e figuras; realização de cálculos e projeções; redação do manuscrito; adequação do manuscrito às normas da RTA.

Vania Beatriz Merlotti Herédia: Realização da revisão bibliográfica e fundamentação teórica; escolha dos procedimentos metodológicos; revisão crítica do manuscrito. 